\section{Hereditary hemorrhagic telangiectasia: diagnosis and management from the hematologist's perspective}

\author{
Athena Kritharis, ${ }^{1}$ Hanny Al-Samkari ${ }^{2}$ and David J Kuter ${ }^{2}$ \\ ${ }^{1}$ Division of Blood Disorders, Rutgers Cancer Institute of New Jersey, New Brunswick, NJ \\ and ${ }^{2}$ Hematology Division, Massachusetts General Hospital, Harvard Medical School, \\ Boston, MA, USA
}

\section{ABSTRACT}

$\mathrm{H}$ ereditary hemorrhagic telangiectasia (HHT), also known as OslerWeber-Rendu syndrome, is an autosomal dominant disorder that causes abnormal blood vessel formation. The diagnosis of hereditary hemorrhagic telangiectasia is clinical, based on the Curaçao criteria. Genetic mutations that have been identified include ENG, ACVRL1/ALK1, and MADH4/SMAD4, among others. Patients with HHT may have telangiectasias and arteriovenous malformations in various organs and suffer from many complications including bleeding, anemia, iron deficiency, and high-output heart failure. Families with the same mutation exhibit considerable phenotypic variation. Optimal treatment is best delivered via a multidisciplinary approach with appropriate diagnosis, screening and local and/or systemic management of lesions. Antiangiogenic agents such as bevacizumab have emerged as a promising systemic therapy in reducing bleeding complications but are not curative. Other pharmacological agents include iron supplementation, antifibrinolytics and hormonal treatment. This review discusses the biology of HHT, management issues that face the practising hematologist, and considerations of future directions in HHT treatment.

\section{Introduction}

Hereditary hemorrhagic telangiectasia (HHT), also known as Osler-WeberRendu syndrome, is a common autosomal dominant disorder that causes abnormal blood vessel formation. ${ }^{1}$ The eponym recognizes the $19^{\text {th }}$ century physicians William Osler, Henri Jules Louis Marie Rendu, and Frederick Parkes Weber, who each independently described the disease. ${ }^{2}$ Clinical sequelae of HHT include mucocutaneous telangiectasias, arteriovenous malformations (AVMs), and bleeding, with consequent iron deficiency anemia. Patients with HHT have been found to have abnormal plasma concentrations of transforming growth factor-beta (TGF- $\beta)^{3}$ and vascular endothelial growth factor $(\mathrm{VEGF})^{4}$ secondary to mutations in $E N G$, ACVRL1 and MADH4. ${ }^{5}$ There is considerable inter- and intra-family variation in disease onset and clinical severity, even in cases resulting from an identical mutation. Iron deficiency and associated anemia are frequent complications of the disease due to recurrent epistaxis and/or gastrointestinal bleeding. There are no accepted guidelines on management of patients with HHT beyond supportive measures of iron supplementation, red cell transfusion, and directed treatments to ablate bleeding sites and AVMs.

Bevacizumab, a recombinant humanized monoclonal antibody that blocks angiogenesis via VEGF inhibition, appears to be promising in HHT as an intravenous formulation for reducing the frequency and severity of epistaxis and impacting quality of life. ${ }^{6,7}$ However, data on intranasal bevacizumab have been conflicting, and studies investigating the use of intravenous bevacizumab are limited to case reports and retrospective series. ${ }^{8}$ Treatment of HHT involves a multidisciplinary approach of specialists in cardiology, pulmonology, hepatology, interventional radiology, ear, nose and throat (ENT), genetics, and hematology. This
Haematologica 2018

Volume 103(9):1433-1443

\section{Correspondence:}

hal-samkarimgh.harvard.edu

Received: April 4, 2018.

Accepted: May 14, 2018.

Pre-published: May 24, 2018.

doi:10.3324/haematol.2018.193003

Check the online version for the most updated information on this article, online supplements, and information on authorship \& disclosures: www.haematologica.org/content/103/9/1433

(C)2018 Ferrata Storti Foundation

Material published in Haematologica is covered by copyright. All rights are reserved to the Ferrata Storti Foundation. Use of published material is allowed under the following terms and conditions:

https://creativecommons.org/licenses/by-nc/4.0/legalcode. Copies of published material are allowed for personal or internal use. Sharing published material for non-commercial purposes is subject to the following conditions: https://creativecommons.org/licenses/by-nc/4.0/legalcode, sect. 3. Reproducing and sharing published material for commercial purposes is not allowed without permission in writing from the publisher. 
review focuses on the biology of HHT and the management issues that confront the hematologist, as well as proposing a hematology management scheme.

\section{Pathogenesis}

\section{Pathology}

Hereditary hemorrhagic telangiectasia is a disease characterized by vascular lesions, including AVMs and telangiectasias. AVMs are abnormal connections that form between arteries and veins without an intermediary capillary system. They can occur anywhere in the body, such as in the central nervous system (CNS), lungs, liver or spine. Vascular malformations may be composed of small (nidi $1-3 \mathrm{~cm}$ ) or micro (nidi $<1 \mathrm{~cm}$ ) AVMs, pulmonary sacs, or direct high-flow connections. While the terms "telangiectasia" and "arteriovenous malformation" are often used interchangeably, as they both occur from a direct connection between an artery and a vein whilst bypassing the capillary system, they are actually pathologically-distinct terms. Telangiectasias, by definition, occur on mucocutaneous surfaces, such as the skin, gastrointestinal (GI) mucosa, or upper aerodigestive tract. AVMs occur in internal organs, such as the liver, lung, and brain. ${ }^{9}$ Histological evaluation of AVMs reveals an irregular endothelium, increased collagen and actin, and a convoluted basement membrane. ${ }^{10}$

\section{Gene mutations}

Gene mutations that have been described in HHT include ENG, ACVRL1 (also known as ALK1), and MADH4 (also known as SMAD4), as well as other postulated loci (Table 1). ${ }^{11,12}$

- In 1994, ENG, located on chromosome 9q34 and encoding for the protein endoglin (CD105), was the first gene identified in which mutations resulted in HHT, and so HHT due to ENG mutations is known as HHT type 1 (HHT1) ${ }^{13}$ Endoglin is a cell-surface glycoprotein that functions as part of the transforming growth factor beta (TGF$\beta)$ signaling complex that plays an important role in angiogenesis and vascular remodeling. ${ }^{14,15}$

- In 1996, defects in the ACVRL1 gene on chromosome $12 \mathrm{q} 13$, which encodes for the activin receptor-like kinase 1 (ALK1), were recognized to cause HHT, and defects in this gene result in HHT type 2 (HHT2). Like endoglin, ALK1 is a cell-surface protein that is part of the TGF- $\beta$ signaling pathway and is important in the regulation of angiogenesis. ${ }^{16}$
- Mutations in MADH4 (which encodes for the SMAD4 protein, a transcription factor that mediates signal transduction in the TGF- $\beta$ pathway ${ }^{17}$ ) result in a juvenile polyposis with HHT syndrome (JP-HHT), described later in this review.

Over $80 \%$ of HHT patients have identifiable mutations, ${ }^{18,19}$ leaving approximately $20 \%$ who meet clinical diagnostic criteria but do not have definitive mutations. Of those with a pathogenic mutation, $61 \%$ have ENG mutations, $37 \%$ have ACVRL1 mutations, and $2 \%$ have $\mathrm{MADH} 4$ mutations; ${ }^{20}$ very small minorities of patients have pathogenic mutations in other genes, described below. Over 600 different mutations have been uncovered in ENG and ACVRL1 in all exons as well as exon/intron boundaries and splice-sites. ${ }^{21}$ Frameshift and nonsense mutations appear to be more frequent in ENG.

Additional loci associated with HHT have been identified on chromosomes 5q31 (HHT3) and 7q14 (HHT4), but have not been completely characterized. ${ }^{20,22,23}$ Bone morphogenetic protein 9 (BMP9, also known as growth differentiation factor 2 or GDF2), encoded by BMP9 (also called GDF2), is a ligand for the ACVRL1 gene product ALK1. Consequently, mutations in $B M P 9 / G D F 2$ result in the clinical manifestations of HHT and are referred to as HHT5. In addition, pathogenic mutations in the RASA1 gene have also been associated with a clinical syndrome consistent with $\mathrm{HHT}^{24}$ as well as other vascular anomalies. Little is known about RASA1-mutated HHT.

\section{Pathophysiology}

All three identified causative genes are involved in cell signaling via the TGF- $\beta$ /BMP signaling pathway, which has roles in cell growth, apoptosis, smooth muscle cell differentiation, and vascular remodeling and maintenance. ${ }^{25}$ The vasculature normally develops from the capillary system with the activation and growth of endothelial cells, the intercellular junctions between them, and the maturation of the basement membrane. ${ }^{26}$ Capillaries then develop into larger vessels with the recruitment of smooth muscle cells to the endothelial wall where TGF- $\beta$ is essential.

In the healthy patient, ligands in the extracellular space such as TGF- $\beta$, activins and BMPs bind to type I and type II serine/threonine receptors of the cell membrane. TGF$\beta 1 / 2 / 3$ ligand binds to the type II receptor of the TGF- $\beta$ signaling cascade (TGF $\beta$ RII) that becomes phosphorylated and recruits the TGF- $\beta$ type I receptors ALK1 or ALK5. ${ }^{27}$ Endoglin is an endothelial specific receptor that associates

Table 1. Classification and genetics of the most common hereditary human telangiectasia (HHT) subtypes.

\begin{tabular}{|c|c|c|c|}
\hline Disease & $\begin{array}{l}\text { Genetic mutation } \\
\text { (locus) }\end{array}$ & $\begin{array}{l}\text { Primary visceral } \\
\text { manifestations }\end{array}$ & $\begin{array}{l}\text { Function of normal } \\
\text { gene product }\end{array}$ \\
\hline HHT type 1 & $E N G(9 \mathrm{q} 34.11)$ & $\begin{array}{l}\text { Pulmonary AVMs } \\
\text { Brain AVMs }\end{array}$ & $\begin{array}{l}\text { Membrane glycoprotein receptor on } \\
\text { endothelial cells, part of the transforming growth factor- } \\
\text { beta (TGF- } \beta \text { ) receptor complex }\end{array}$ \\
\hline HHT type 2 & ACVRL1 (ALK1;12q13.13) & $\begin{array}{l}\text { Liver AVMs } \\
\text { Pulmonary hypertension } \\
\text { Spinal AVMs }\end{array}$ & $\begin{array}{l}\text { Activin receptor-like kinase } 1 \text { (ALK1), a cell-surface } \\
\text { serine/threonine-protein kinase receptor, part of the } \\
\text { TGF- } \beta \text { receptor complex }\end{array}$ \\
\hline $\begin{array}{l}\text { Combined syndrome } \\
\text { of HHT and JP-HHT }\end{array}$ & MADH4 (SMAD4; 18q21.2) & $\begin{array}{l}\text { Gastrointestinal polyps } \\
\text { AVMs } \\
\text { Pulmonary hypertension }\end{array}$ & $\begin{array}{l}\text { MADH4 encodes SMAD4, a transcription factor acting } \\
\text { as a mediator in the TGF- } \beta \text { /BMP pathway signaling }\end{array}$ \\
\hline
\end{tabular}

AVM: arteriovenous malformations; JP-HHT: juvenile polyposis-HHT. 
with multiple receptor complexes of the TGF- $\beta$ receptor complex and also modulates ALK1 and ALK5. ${ }^{27,28}$ Circulating BMP9 has been demonstrated to bind strongly with endoglin and ALK1 receptors found abundantly in the surface membrane of endothelial cells. ${ }^{29}$ ALK1 receptors phosphorylate SMAD1/5/8 in the cytoplasm to form the SMAD1/5/8-SMAD4 complex that translocates to the nucleus to promote normal endothelial cell proliferation and smooth muscle migration. In contrast, the ALK5 pathway works through SMAD2/3 to inhibit normal endothelial cell proliferation and smooth muscle migration. ${ }^{27,28,30}$ The result is contrasting responses that balance endothelial proliferation, angiogenesis and smooth muscle migration.

In patients with HHT, mutations in endoglin, ALK1, or one of several other proteins in this pathway alter the normal endothelial response. In HHT1, the ENG mutation leads to reduced endoglin, ALK1 and ALK5 signaling; in HHT2, the ALK1 mutation causes reduced ALK1 signaling alone. Mice with one functioning copy of Eng or Acvrll show clinical signs of HHT. ${ }^{31}$ The haploinsufficiency of these proteins along with a second hit, such as tissue injury, infection or hypoxia, likely cause the focal vascular lesions of HHT1 and HHT2 as reduced levels of endoglin or ALK1 cannot maintain the balance needed for normal blood vessel formation (recruitment of smooth muscle cells and proliferation of endothelial cells). ${ }^{26,32}$ Decreased TGF- $\beta$ transcription normally mediated through this pathway, therefore, disrupts the vascular integrity and smooth muscle differentiation of the endothelium resulting in an abnormal cytoskeleton and fragile small vessels.

Vascular endothelial growth factor, an endothelial-specific factor for angiogenesis, is of major interest in diseases of vascular malformation and is elevated in HHT patients. ${ }^{33}$ VEGF production is stimulated by ALK5 (and SMAD2 through activation of ALK5) and inhibited by ALK1 (and SMAD1 through activation of ALK1). ${ }^{34}$ Therefore, any mutation along the ALK1 pathway (BMP9, ACVRL1, ENG, MADH4) results in elevation of VEGF through reduced ALK1 pathway signaling. VEGF drives many of the pathogenic manifestations of HHT, as normalizing VEGF has been shown to prevent AVMs in Acvrl1-deficient mice..$^{35}$ This may be secondary to reduced angiogenic stimuli and reduction of feeding arteries from blocking the VEGF that would normally develop and maintain arteriovenous shunts.

Other factors that may contribute to the severity of disease include repeated injury and chronic inflammation in keeping with the two-hit hypothesis and stimulation of the ALK1 signaling pathway. An abnormal endothelium

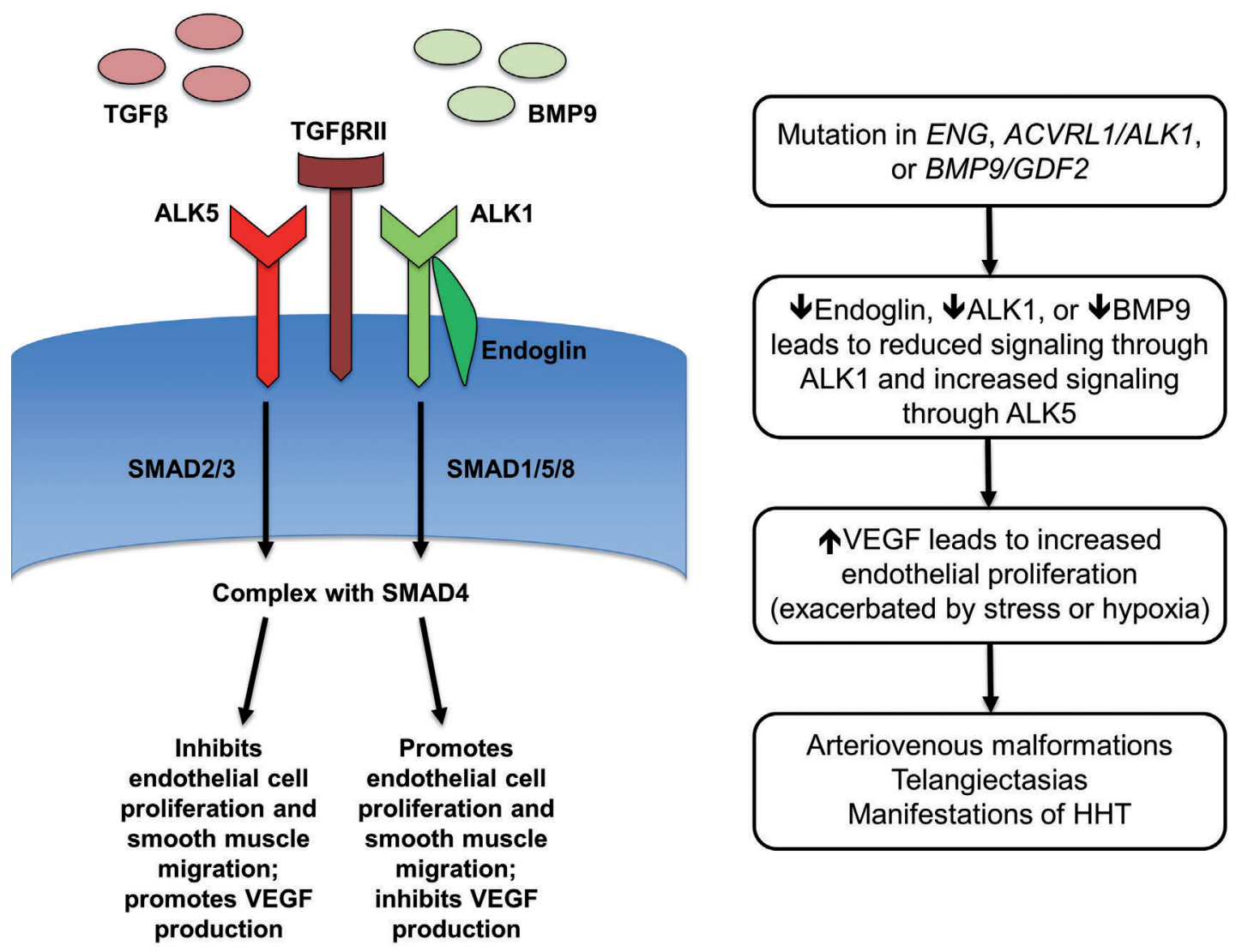

Figure 1. Molecular pathophysiology of hereditary hemorrhagic telangiectasia (HHT). Physiological signaling via ALK1 and ALK5 receptors (activated via binding BMP9 and TGF $\beta$ ) results in activation of different SMAD pathways, which converge at SMAD4 resulting in transcription of genes involved in angiogenesis. ${ }^{30}$ In HHT, mutations perturb signaling through ALK1 via mutations in the ALK1 receptor itself, its ligand BMP9, or its modulator, the glycoprotein membrane receptor endoglin. The result is decreased signaling through ALK1 and increased signaling through ALK5, perturbing normal endothelial proliferation and smooth muscle cell migration. Reduced ALK1 signaling and increased ALK5 signaling also result in higher vascular endothelial growth factor (VEGF) levels, causing increased endothelial proliferation (which may be exacerbated by stress or hypoxia), resulting in arteriovenous malformations (AVMs), telangiectasias, and the manifestations of HHT. 
may also lead to defective synthesis of von Willebrand Factor (VWF) and prolonged bleeding. There have been reports of families affected by both von Willebrand disease (VWD) and HHT. This poses the question of a potential relationship between the two diseases, which has been studied in published case reports. A potential type IIA VWD mutation (IIe865 to Thr) has been identified in affected families. ${ }^{36}$

While this is a simplified discussion of complex vascular biology, it illustrates why mutations in ENG, ACVRL1/ALK1, MADH4/SMAD4, and BMP9/GDF2 result in the HHT phenotype. A streamlined schematic summarizing the normal physiological signaling of the TGF- $\beta$ pathway and the pathophysiology of HHT is shown in Figure 1.

\section{Epidemiology and disease course}

Hereditary hemorrhagic telangiectasia affects approximately 1 in 5000 individuals in North America, ${ }^{37}$ but the highest prevalence is seen in the Afro-Caribbean regions of the Dutch Antilles and France. ${ }^{38}$ There is also variability regarding HHT subtype, with type 1 HHT being found more in North America and Europe and type 2 being more common in the Mediterranean and South America. However, these statistics may underestimate the actual disease prevalence as the diagnosis is often missed and some patients may be asymptomatic. HHT exhibits incomplete penetrance and clinical manifestations can vary between patients, even within families with known mutations.

Patients may relate a history of epistaxis in childhood, often apparent during adolescence. Mild epistaxis or bleeding tendencies increase with age and telangiectasias may be seen after adolescence, often in adulthood. ${ }^{1}$ Clinical signs of bleeding become more apparent in adulthood, often after the age of 40 years. Symptoms from anemia may be an initial complaint at presentation from gastrointestinal bleeding, seen in approximately one-third of patients. Patients with mutations of ACVRL1 may present later in life, while those with MADH4 mutations may present earlier in childhood with juvenile colonic polyps and early onset colorectal cancer (at a mean age of 28 years)..$^{1,39}$

As a population, patients with HHT probably have a reduced life expectancy, but this is highly dependent on the severity of disease. Patients without internal organ manifestations (such as hepatic, cerebral or pulmonary AVMs) are expected to have a normal or near-normal lifespan, but approximately $10 \%$ of patients may die or become debilitated from vascular complications. ${ }^{40}$ In a large case-control study, 675 HHT patients were compared with age- and sex-matched healthy controls using a population-based UK primary care database. Patients with HHT were more likely to suffer from cerebral abscess, migraine, ischemic/embolic stroke, heart failure, colon cancer, and the numerous bleeding complications characteristic of the disease. The hazard ratio for death for patients with HHT compared with controls was 2.03 (CI: 1.59-2.60; $P<0.0001) .{ }^{41}$ Life expectancy was seven years shorter in HHT patients in one study, with two mortality peaks, one under 50 years and one between 60-79 years of age. ${ }^{42}$ Finally, a population study in Denmark demonstrated mortality rates double that of the general population in those under 60 years of age. ${ }^{43}$

\section{Clinical manifestations}

Patients with HHT vary in disease severity and bleeding complications. This variability is likely attributed to other genes, inflammation, and the environment that modify the primary genetic defect. Common AVM complications include epistaxis, GI bleeding, iron deficiency, iron deficiency anemia, ischemic and hemorrhagic stroke, brain abscess, high output heart failure, and liver failure.

It is suggested that certain mutated genes in HHT may be associated with specific clinical manifestations. ENG mutations may be associated with more pulmonary and brain AVMs; ACVRL1 with more liver AVMs, spinal AVMs, epistaxis and pulmonary hypertension; and MADH4 with juvenile colonic polyposis. ${ }^{44}$

\section{Pulmonary AVMs}

Pulmonary AVMs will develop in at least $50 \%$ of HHT patients and are more common in HHT1 than HHT2. Since approximately $70 \%$ of pulmonary AVMs are due to HHT, the diagnosis of HHT1 should be considered in all patients with pulmonary AVMs. Migraines are quite frequent in patients with pulmonary AVMs. ${ }^{45}$ Between 5 and $30 \%$ of patients may have pulmonary AVMs that may be asymptomatic or present as hemoptysis, dyspnea, hypoxemia or digital clubbing. Brain abscesses and stroke may occur following "dirty" procedures (e.g. dental cleaning) if bacteria can bypass the pulmonary filtration system via right to left shunting from AVMs. ${ }^{46}$ Polycythemia may occur if there is significant AV shunting. The locus designated as HHT3 appears to predispose to pulmonary AVM formation.

\section{Liver AVMs}

Liver AVMs may be seen in up to $70 \%$ of patients with HHT. HHT2 appears to be associated with more liver AVMs. Although often asymptomatic, the shunting of blood through these AVMs in the liver can precipitate highoutput heart failure, liver failure, or portal hypertension.

\section{High-output heart failure}

High-output heart failure can manifest due to large pulmonary AVMs and/or hepatic AVMs. ${ }^{47}$ High-output failure can be defined by: 1) symptoms of heart failure (such as shortness of breath, fatigue, and exercise intolerance); 2) cardiac output $>8 \mathrm{~L} / \mathrm{min}$ or cardiac index $>3.9 \mathrm{~L} / \mathrm{min} / \mathrm{m}^{2}$; and 3 ) ejection fraction (EF) $>50 \%$ and venous oxygen saturation $>75 \% .^{48}$ Due to abnormal vascular flow through AVMs of the liver or lung, the vasculature may dilate because of increased high flow and/or decreased resistance. This causes the heart to compensate for the lower blood pressure with an increase in heart rate and output, leading to high-output failure. In these HHT patients, anemia may lead to an increased risk of heart failure due to the stress imposed from tachycardia and increased stroke volume.

\section{Epistaxis}

Epistaxis will manifest in approximately $50 \%$ of patients by the age of ten years. This increases with age such that 95\% of all HHT patients eventually develop recurrent epistaxis. ${ }^{49}$ This will become evident in adulthood with consequent iron deficiency anemia.

\section{Gastrointestinal bleeding}

When significant, gastrointestinal bleeding affects approximately $20 \%$ of patients. GI telangiectasias and 
AVMs can involve the large and small intestines as well as the stomach.

\section{Central nervous system manifestations}

Central nervous system manifestations may affect up to $10 \%$ of patients with HHT. Cerebral AVMs can be symptomatic and multiple in number, ${ }^{50}$ and are often present at birth. ${ }^{51}$ Neurological involvement may result in epilepsy, transient ischemic attack, stroke, or spinal hemorrhage. In addition to embolic strokes and hemorrhage, CNS infections such as brain abscesses may occur in $1 \%$ or more of patients, ranging in severity from mild to lifethreatening. They are likely a result of bacterial seeding or septic emboli from ischemic brain matter or pulmonary AVMs. ${ }^{52,53}$

\section{Skin telangiectasias}

Skin telangiectasias can be seen on the fingertips, tongue, face, lip, mucosa, and arms in up to $90 \%$ of patients (Figure 2). ${ }^{45}$ These sites can bleed and can be treated with laser ablation.

\section{Iron deficiency/iron deficiency anemia}

Iron deficiency/iron deficiency anemia is common in HHT. The underlying cause of iron deficiency in this patient population is the chronic blood loss from telangiectasias (e.g. nasal mucosa or intestinal tract) leading to iron store depletion. Approximately $5 \%$ of patients with HHT may have severe hemorrhages from epistaxis and/or intestinal AVMs. This consequently leads to a microcytic or normocytic anemia and symptoms of fatigue. Cardiopulmonary complications as described above can develop.

\section{Other events}

Though other events are not frequently reported, they include thromboembolic disease, pulmonary hypertension, liver disease, high-risk pregnancies, and spinal events. There is a $1 \%$ risk of mortality during pregnancy due to hemorrhage from cerebral or pulmonary AVMs. ${ }^{44}$ Patients are also affected socially and psychologically due to uncontrolled bleeding episodes. They commonly face difficulties with work, travel, social phobias, isolation, anxiety, and depressive disorders.

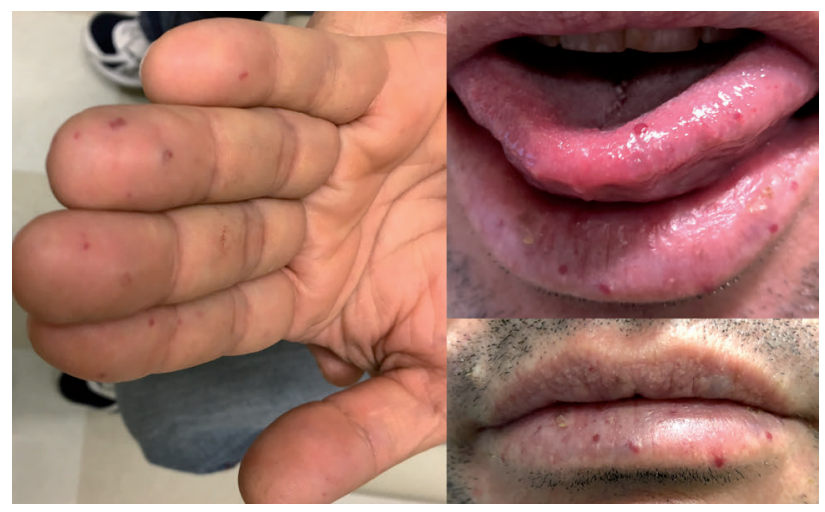

Figure 2. Clinical manifestations of telangiectasias. (A) Small red telangiectasias are often seen on the skin of hereditary hemorrhagic telangiectasia patients. (B) Similar lesions may be present on the tongue, lips, or palate.

\section{Juvenile polyposis}

Juvenile polyposis is a rare association with HHT and results from a germline mutation in MADH4. ${ }^{54}$ This condition is also an autosomal dominant disorder. Mutations in MADH4 may manifest phenotypically as juvenile polyposis alone, HHT alone, or the combined syndrome of JPHHT. ${ }^{55}$ The polyposis is best characterized by numerous hamartomatous polyps (i.e. 5-100) that are typically benign, but some patients may develop gastric or colorectal cancer, and so screening is encouraged. Patients with JP-HHT associated with MADH4 mutations are at an increased risk for early colorectal cancer. ${ }^{44}$ These patients may also have thoracic aorta dilation.

\section{Diagnosis}

Hereditary hemorrhagic telangiectasia is primarily a clinical diagnosis based on the following Curaçao criteria: ${ }^{44}$

- spontaneous and recurrent epistaxis

Table 2. Screening and management of hereditary human telangiectasia patients.

\section{Anemia}

- Evaluate for blood transfusion and iron requirements

- Monitor ferritin, reticulocytes, hemoglobin

- Start oral iron to maintain transferrin saturation $>20 \%$ and ferritin $>50 \mathrm{ng} / \mathrm{mL}$

- IV iron: $1 \mathrm{~g}$ over multiple infusions

\section{Epistaxis}

- Otolaryngology evaluation

- Humidification

- Nasal moisture with spray/ointment

- Electrocautery or laser therapy

- Antifibrinolytics, estrogen or progesterone therapy, surgery, and embolization

\section{Gastrointestinal bleeding}

- Evaluation for telangiectasias and AVMs with upper endoscopy, colonoscopy, capsule endoscopy

- Antifibrinolytics, estrogen or progesterone therapy, laser therapy, surgery, and embolization

\section{CNS AVM}

- MRI/MRA brain

- $>1 \mathrm{~cm}$ in diameter: neurosurgical evaluation, embolotherapy, + - stereotactic radiosurgery

\section{Pulmonary AVM}

- Pulmonary evaluation

- Transthoracic echocardiogram with bubble study for screening + - CT/CTA

- If 1+ bubbles on echocardiogram: avoid scuba diving, use IV with filters, antibiotic prophylaxis for procedures (amoxicillin or clindamycin if PCN allergic)

- Consider embolization

\section{Hepatic AVM}

- Abdominal ultrasound screening +/- CT/MRI

- Consider embolization/ligation, liver transplantation

Other

- Genetic consultation

- Evaluation for other bleeding disorders

- Discussion regarding anticoagulation, antiplatelet agents

- Pregnancy is considered high risk

- Consider assessment for hypercoagulability

IV: intravenous; CNS: central nervous system; AVM: arteriovenous malformation; CT computed tomography; MRI: magnetic resonance imaging; MRA: magentic resonance angiography; CTA: CT angiography; PCN: penicillin. 
- telangiectasias at characteristic sites

- visceral arteriovenous malformations or telangiectasias

- a first degree relative with HHT (inheritance is usually autosomal dominant).

Patients are classified as follows:

3-4 criteria: definite HHT

2 criteria: probable HHT

0-1 criteria: HHT unlikely.

Genetic testing can be performed to inform family members, to increase patient awareness, and can guide more focused preventative screening and in cases of uncertainty. For patients with all 4 features present, the clinical sensitivity of the 5 gene HHT panel (assessing for pathogenic mutations in ENG, ACVRL1, MADH4, RASA1, and BMP9) is approximately $87 \%$ or higher. ${ }^{19}$ Although there has recently been an increase in awareness of HHT, it has been estimated that only $10 \%$ of all HHT patients are formally diagnosed; this is because of minimal symptoms or the fact that caregivers are not familiar with the disease and its diagnostic criteria. ${ }^{56}$

\section{Assessment and management}

The prevention of future HHT complications is as important as treating the immediate active issues (e.g. bleeding) in caring for patients with HHT. Patients are often asymptomatic from undiagnosed AVMs that can lead to significant morbidity and mortality. Knowledge of a patient's genetic mutation or family history may help confirm the urgency of certain screening tests over others. As outlined in Table 2, the following are relevant measures for identifying potentially significant AVMs: 1) brain magnetic resonance imaging (MRI)/magnetic resonance angiography (MRA); 2) transthoracic echocardiogram with bubble study, followed by computed tomography (CT) scan as appropriate; 3) colonoscopy/endoscopy/video capsule endoscopy; 4) abdominal doppler ultrasound of the liver, followed by CT scan or MRI as indicated; 5) full ENT evaluation (especially if the patient has epistaxis); and 6) skin evaluation. Hematologic evaluation must also include complete blood count, reticulocyte count, erythrocyte sedimentation rate, iron, total iron binding capacity and ferritin. Ferritin levels alone may not accurately reflect iron stores due to the increased inflammation seen in many HHT patients. Consideration should be given to assessment for inherited thrombophilias prior to using antifibrinolytics for treatment of bleeding associated with HHT.

Treatment options are patient-specific and are best grouped by local versus systemic measures in a stepwise approach. There are no standard medical therapies for HHT given the few randomized trials in this field. Management can include supportive care, lesion-specific therapy, and systemic treatment. Lesion-specific therapy may call for involvement from otolaryngology, interventional radiology and neurosurgery.

\section{Management of epistaxis}

The first step in epistaxis management should always be appropriate patient counseling and use of preventive measures within the home to prevent the nasal mucosa from becoming dry. These may include nasal humidification, use of over-the-counter saline sprays or ointments to keep the nasal mucosa moist, and avoidance of nasal trauma (i.e. from nose blowing and/or nose picking). ${ }^{20}$
When epistaxis occurs that does not cease within a short period of time at home, nasal packing and direct use of topical agents such as tranexamic acid-soaked gauze in an outpatient clinic or emergency room setting may help curtail bleeding but may also increase trauma to the nasal mucosa. Additional local measures that are commonly employed to control bleeding include laser treatments to the nasal mucosa and septodermoplasty. ${ }^{57}$ Historically, laser photocoagulation and other interventional procedures have been the cornerstone of therapy, ${ }^{58}$ although this may begin to shift with effective disease-modifying systemic therapeutics on the horizon, detailed later in this review. Nasal closure ${ }^{57}$ is an effective but extreme form of therapy that is rarely used.

Management of epistaxis with antifibrinolytic agents is another consideration when preventive measures and local or topical treatments fail. Hyperfibrinolysis contributes to the bleeding phenotype in $\mathrm{HHT}^{59,60}$ and antifibrinolytics may work to inhibit fibrinolysis on the telangiectatic wall. By preventing fibrin degradation from plasmin, these agents may act to slow bleeding. Epsilonaminocaproic acid and tranexamic acid can be considered in the care of patients with moderate or severe epistaxis. ${ }^{61}$ In a randomized, double-blind, placebo-controlled, crossover study of 22 patients, tranexamic acid $1 \mathrm{~g} 3$ times daily resulted in a $54 \%$ reduction in nosebleeds while on tranexamic acid as compared with the placebo treatment period, although there was no statistically significant improvement in hemoglobin concentration. ${ }^{62}$ Apart from its inhibition of plasmin, tranexamic acid may have some effect on the underlying disease process; it appears to increase endoglin and ALK1 levels on the endothelium, selectively stimulating the TGF- $\beta$ pathway. ${ }^{63}$ Tranexamic acid may have a higher potency and longer half-life than aminocaproic acid in these patients. ${ }^{63}$ Dosing can be titrated upward if tolerable to tranexamic acid 650-1300 mg orally 3 times daily or aminocaproic acid 500-2000 mg orally every 4-8 hours. ${ }^{63}$ Other non-specific hemostatic agents, such as desmopressin or factor replacement products, are not optimal management as HHT is not a disease of coagulation factor deficiency. Antifibrinolytics should be avoided in patients with hypercoagulable conditions and/or prior thrombotic events.

While the evidence for its use is limited, N-acetylcysteine dosed $600 \mathrm{mg} 3$ times daily was modestly effective in reducing epistaxis in HHT patients in a pilot study, with the only statistically significant benefit seen in male patients and those with ENG mutations (HHT1). ${ }^{64}$

\section{Management of GI bleeding}

Evidence of GI bleeding or a sharp decline in hematocrit without epistaxis should involve a prompt GI evaluation and an upper and lower endoscopy and, if these do not provide clear results, consideration of video capsule endoscopy. Telangiectasias and AVMs may be visualized in the esophagus, stomach, small intestine and/or colon. ${ }^{65}$ If accessible, local endoscopic treatment should be attempted. Patients with recurrent bleeding, multiple AVMs, and small bowel AVMs may require additional pharmacological measures. As in the management of epistaxis, antiangiogenic, antifibrinolytic agents and/or other hormonal agents may be considered. Octreotide therapy has also been proposed in reducing transfusion needs ${ }^{66}$ but is without much supporting data. Management of the ane- 
mia and iron deficiency that result from this blood loss is addressed below.

\section{Management of pulmonary, hepatic, and CNS AVMs}

Collaboration with a pulmonologist, hepatologist, gastroenterologist, neurologist, neurosurgeon, and interventional radiologist with experience in treating HHT patients is crucial to the management of AVMs found in the lungs, liver or brain. Screening is, therefore, important early in the diagnosis of these patients. Management will depend on the size of the AVMs, symptoms and location, and may include embolization of a pulmonary AVMs, surgical intervention for a CNS AVM and/or continued surveillance. Angiographic treatment of hepatic AVMs may be helpful in some patients but is often considered a higher risk by interventional radiologists.

\section{Management of iron deficiency anemia}

The development of anemia can have significant consequences for the patient with HHT. Although oral iron [e.g. ferrous sulfate $325 \mathrm{mg} 3$ times daily, ferrous asparto glycinate-polysaccharide iron complex $150 \mathrm{mg}$ capsules 1-3 times daily] may be adequate for mildly affected HHT patients, many require intravenous iron such as ferumoxytol, iron sucrose or ferric carboxymaltose. Some patients may require 500-1000 mg of iron a month. Sometimes red blood cell (RBC) transfusion support is needed, but chronic $\mathrm{RBC}$ transfusion carries risk of infections and can lead to transfusion reactions and alloimmunization. In some patients, supplementation with erythroid stimulating agents (e.g. epoetin alfa, darbepoetin alfa) may be helpful. A suggested approach to the anemic HHT patient is presented in Figure 3.

\section{Use of hormonal agents}

Estrogen and progestins (e.g. ethinyl estradiol, norethindrone or mestranol) have been used in HHT patients to reduce bleeding complications. Mestranol or norethynodrel may help increase nasal squamous epithelium and protect nasal lesions from injury. This hormonal therapy, however, can result in gynecomastia and/or loss of libido in men, weight gain, coronary events, and venous thromboembolism (VTE). Given the age of some patients and the potential side effects of this treatment, it has not been widely used. The overall improvement in hematologic parameters is also questionable.

Other hormonal treatment options include danazol 200 mg 3-4 times oral daily, tamoxifen $20 \mathrm{mg}$ oral daily or raloxifene $60 \mathrm{mg}$ oral daily. ${ }^{67}$ But these are not widely used.

\section{Use of novel systemic anti-angiogenic therapies}

Anti-VEGF therapies are relatively new for patients with HHT, and their use has been increasing. Thalidomide, used commonly in the management of multiple myeloma, is thought to have both vascular and immunomodulatory effects. Its antiangiogenic activity may be due to the suppression of production of VEGF and basic fibroblast growth factor (bFGF) ${ }^{68}$ Serum levels of VEGF were found to be decreased after thalidomide treatment in patients with GI bleeding. ${ }^{69}$ Nasal mucosal biopsies in HHT patients with epistaxis treated with thalidomide demonstrated vessel maturation and improved vessel wall defects. ${ }^{70}$

Bevacizumab, an anti-VEGF antibody, is a rational therapeutic for HHT as it may reduce excessive angiogenesis (Figure 4). To date, all of the studies describing the use of systemic bevacizumab for the management of HHT have been retrospective cohorts, small case series, or single patient case reports (Table 3). A very recent retrospective study by Iyer et al. describes a large cohort of HHT patients receiving bevacizumab to treat GI bleeding and epistaxis. ${ }^{8}$ Thirty-four patients were given intravenous bevacizumab according to a standardized protocol, resulting in a statistically significant reduction in epistaxis sever-

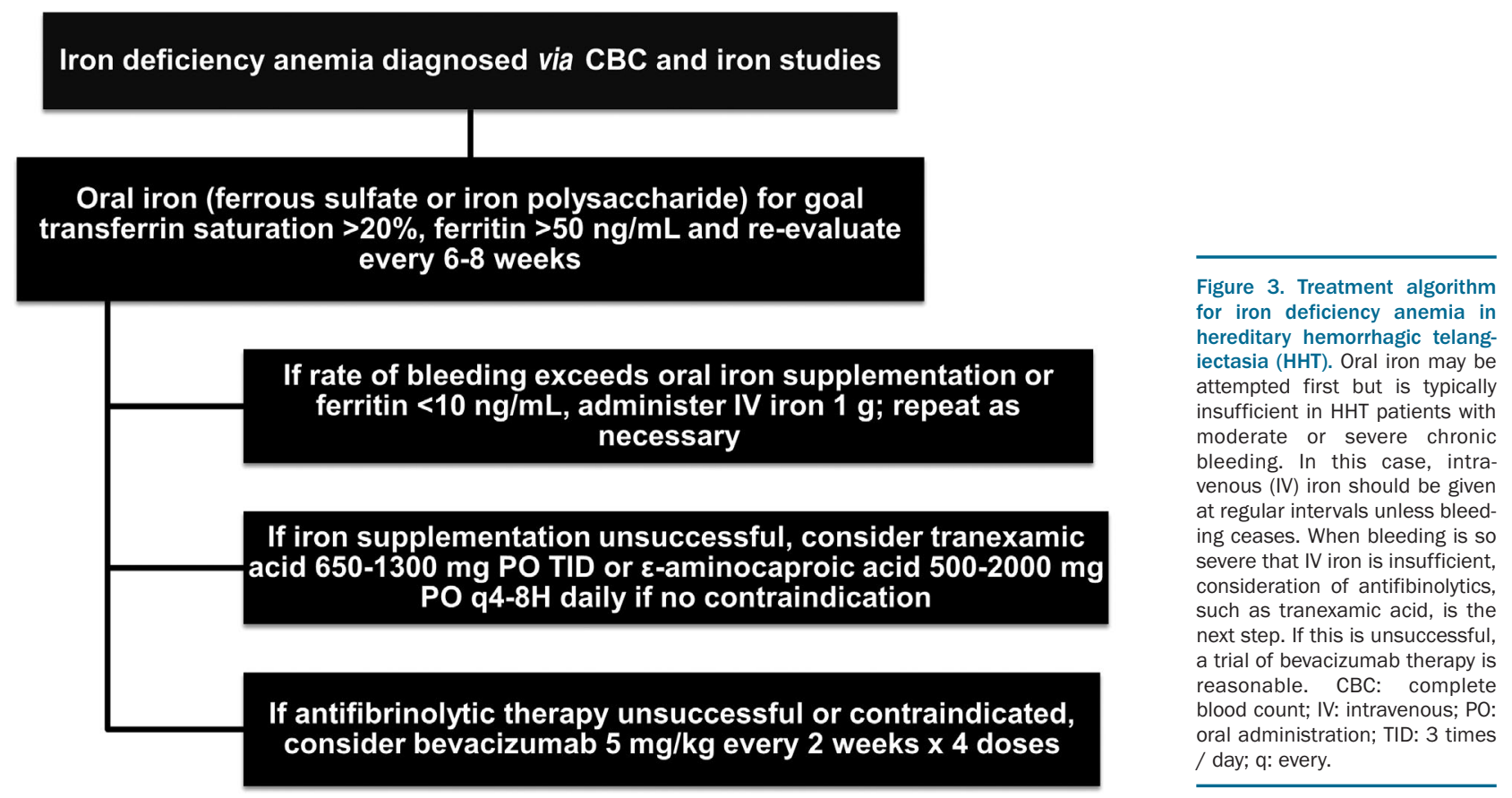


ity scores and RBC transfusion requirements, although 4 patients developed new-onset or worsened hypertension. Most published studies have used bevacizumab at a dose of $5-10 \mathrm{mg} / \mathrm{kg}$ every 2-4 weeks for up to 6 cycles. A lower dose may be sufficient based on pharmacokinetic data showing VEGF suppression at $0.3 \mathrm{mg} / \mathrm{kg} .{ }^{71}$ Adverse effects of bevacizumab may include hypertension, proteinuria, venous thromboembolism, intestinal perforation, and poor wound healing. Interestingly, epistaxis, which is often cited as a side effect in non-HHT patients, has not been a major complication in published studies or in our center's extensive experience. Bevacizumab may have an impact on high output states in reducing cardiac output. In one study, ${ }^{48} 25$ patients with severe hepatic vascular AVMs were treated with bevacizumab $5 \mathrm{mg} / \mathrm{kg}$ every 14 days for 6 cycles and showed an improvement in cardiac index at three months, reduced epistaxis, and improved quality of life. Bevacizumab nasal spray has been studied as a treatment for epistaxis. In a randomized phase I study (the ELLIPSE study), 40 patients received a single day treatment of $0.05-0.1 \mathrm{~mL}$ of (dose escalated) bevacizumab nasal spray into each nostril for a total dose of 12.5-100 mg. ${ }^{72}$ Initial results suggested that intranasal treatment was safe but not effective.

\section{Use of anticoagulation in patients with thrombosis}

Patients who develop thrombotic complications present a difficult therapeutic dilemma given the inherent bleeding of the disease. The low serum iron levels in HHT patients have been associated with elevated factor VIII levels, along with a 2.5 -fold increased risk of VTE events. ${ }^{67}$ In those patients who develop a VTE, therapeutic anticoagulation can be administered. This should be managed with caution and the patient should be screened for pul-

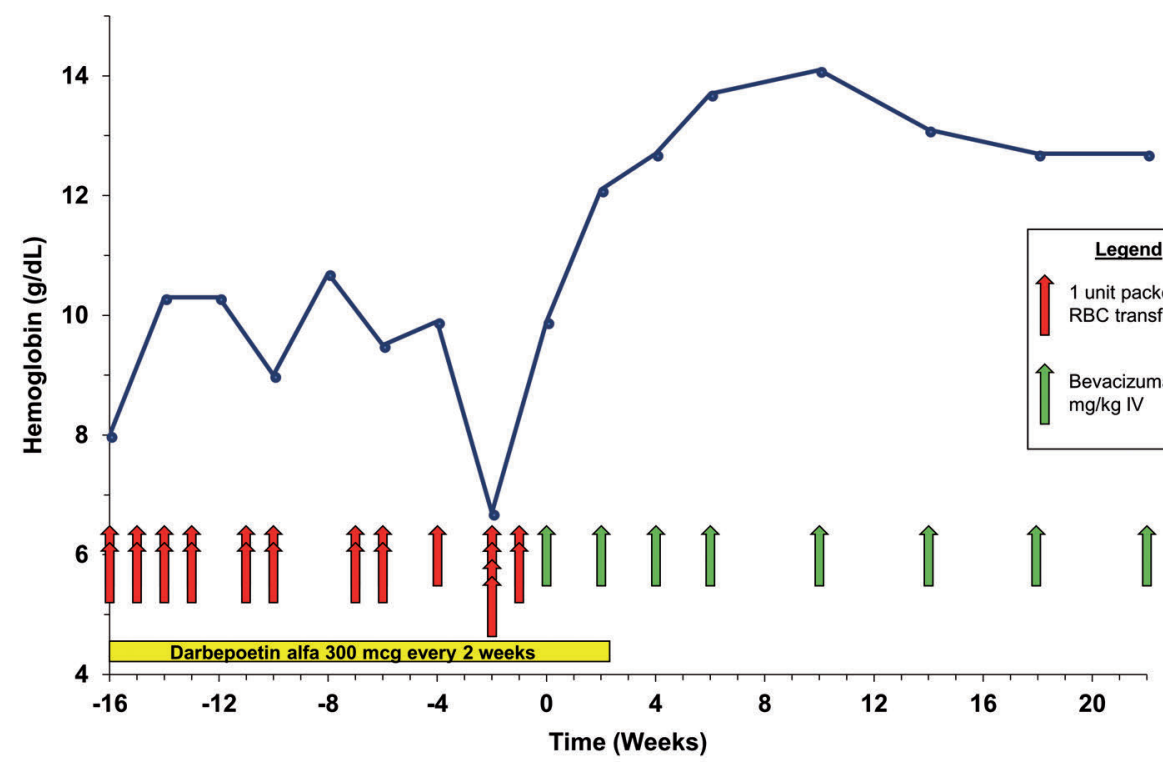

Figura 4. Bevacizumab treatment course in a 71-year-old woman with hereditary hemorrhagic telangiectasia (HHT) and chronic gastrointestinal bleeding and epistaxis. For years, the patient was only able to maintain her hemoglobin with 1-2 units of packed red blood cell (RBC) transfusion weekly plus darbepoetin alfa $300 \mathrm{mcg}$ every other week. After beginning bevacizumab 5 $\mathrm{mg} / \mathrm{kg}$ at time 0 , she became transfusion independent immediately and her hemoglobin normalized within two weeks. Bevacizumab was administered every other week for the first 4 infusions, then monthly as maintenance. Duration of maintenance therapy is patientdependent and optimal dose and duration is not known.

Table 3. Published data using bevacizumab to treat chronic bleeding in hereditary human telangiectasia are patients.

\begin{tabular}{|c|c|c|c|c|c|}
\hline Study & Country & $\begin{array}{l}\text { Patient } \\
\text { number }\end{array}$ & Dosing & Duration of efficacy & Effect on epistaxis \\
\hline Bose $2009^{77}$ & U.S. & 1 & $\begin{array}{c}10 \mathrm{mg} / \mathrm{kg} \text { every } 2 \text { weeks } \times 2 \text { cycles } \\
\text { then } 5 \mathrm{mg} / \mathrm{kg} \text { every } 2 \text { weeks } \times 2 \text { cycles }\end{array}$ & 12 months & Immediate improvement \\
\hline Oosting $2009^{78}$ & the Netherlands & 1 & $\begin{array}{c}5 \mathrm{mg} / \mathrm{kg} \text { every } 2 \text { weeks or } 7.5 \mathrm{mg} / \mathrm{kg} \\
\text { every } 2 \text { weeks }\end{array}$ & 12 months & Immediate improvement \\
\hline Brinkerhoff $2011^{79}$ & U.S. & 1 & 5 mg/kg every 2 weeks x 4 cycles & 12 months & Resolution after 4 cycles \\
\hline Thompson $2014^{80}$ & U.S. & 9 & $0.125 \mathrm{mg} / \mathrm{kg}$ IV every 4 weeks $\mathrm{x} 6$ cycles & 6 months & $\begin{array}{c}\text { Improvement in frequency } \\
\text { and severity after } 3 \text { cycles } \\
\text { on average }\end{array}$ \\
\hline Epperla $2016^{81}$ & U.S. & 5 & $5 \mathrm{mg} / \mathrm{kg}$ every 2 weeks $\mathrm{x} 6$ cycles & 12 months & $\begin{array}{l}\text { Reduced need for nasal } \\
\text { cautery procedures }\end{array}$ \\
\hline Guilhem $2017^{82}$ & France & $\begin{array}{l}36 \text { treated for } \\
\text { bleeding }\end{array}$ & $\begin{array}{c}5 \mathrm{mg} / \mathrm{kg} \\
\text { every } 2 \text { weeks x } 6 \text { cycles }\end{array}$ & 6 months (median) & $\begin{array}{l}78 \% \text { of patients had } \\
\text { improved bleeding by } \\
\text { physician assessment }\end{array}$ \\
\hline Iyer $2018^{8}$ & U.S. & 34 & $\begin{array}{c}5 \mathrm{mg} / \mathrm{kg} \text { every } 2 \text { weeks } \mathrm{x} 4 \text { cycles, } \\
\text { with modification of dosing depending } \\
\text { on response }\end{array}$ & $\begin{array}{l}6.4 \text { months (median), } \\
\text { intermittent treatment }\end{array}$ & $\begin{array}{l}\text { Significant improvement } \\
\text { in epistaxis severity } \\
\text { scores }\end{array}$ \\
\hline
\end{tabular}


monary and cerebral AVMs that may increase their bleeding risk.

\section{Clinical trials and future directions}

There are several ongoing clinical trials studying new therapies for HHT (Online Supplementary Table S1). HHT is relatively unique in the family of rare bleeding disorders in that several off-the-shelf therapeutics, such as bevacizumab, and the immunomodulatory agents (IMiDs) currently being used are rational targeted therapies that may be highly effective. The majority of studies are currently investigating the use of bevacizumab via different routes of administration (submucosal, topical or intravenous). In a murine model of HHT, four anti-angiogenic agents were studied for their impact on AVM formation. $^{73}$ Sorafenib (a dual Raf kinase/VEGF receptor inhibitor with additional tyrosine kinase targets) and a pazopanib analog (pazopanib is a multi-target tyrosine kinase inhibitor with anti-VEGF receptor properties) were beneficial in improving anemia from bleeding from the GI tract more than from mucocutaneous lesions in the upper aerodigestive tract. A phase II study is being conducted to examine the efficacy of increasing doses of pazopanib, from $50 \mathrm{mg}$ to $400 \mathrm{mg}$ daily, in reducing epistaxis and improving anemia.

Tacrolimus, a calcineurin inhibitor used principally as an immunosuppressive therapy, may have a therapeutic role in HHT. Ruiz et al. identified tacrolimus as an activator of the ALK1-SMAD1/5/8 pathway, improving defects caused by ALK1 loss. ${ }^{74}$ Their data in human embryonic vascular endothelial cells demonstrated that tacrolimus activated
ALK1 HHT mutants unresponsive to BMP9, and inhibited Akt and p38 stimulation by VEGF (normally a major driver of angiogenesis). In a mouse model of HHT, hypervascularization and AVMs were reduced in number by treatment with tacrolimus. Tacrolimus may, therefore, represent yet another off-the-shelf pharmacological option of potential therapeutic benefit in HHT patients.

Lastly, the aforementioned IMiDs are promising. In comparison with thalidomide and lenalidomide, pomalidomide may be a superior potential therapeutic option due to its efficacy and reduced toxicity (such as less peripheral neuropathy and cytopenias). Interim results from a phase I study of pomalidomide in HHT patients have been reported in which its use was associated with reduced bleeding outcomes in a small cohort of patients. ${ }^{75}$ Larger studies are needed to better evaluate the efficacy of this and other IMiDs in the management of bleeding in HHT.

Future directions in HHT may look to evaluate other antiangiogenic agents and other targets of the vascular endothelium. In patients with Heyde syndrome, acquired VWF syndrome occurs due to the loss of large molecular multimers of VWF from high shear stress. ${ }^{76}$ The reduced level of VWF observed in a small case series of patients with $\mathrm{HHT}^{36}$ raises the question of whether VWF replacement may reduce bleeding, as patients with ineffective or low VWF cannot effectively clot. Better understanding of the role of acquired VWF deficiency in the pathogenesis of angiodysplasia in Heyde syndrome may prove useful in the development of novel HHT therapies.

In conclusion, HHT is a rare but poorly recognized genetic bleeding disorder that demands greater attention in order to develop targeted and rational management strategies that are both safe and cost-effective.

\section{References}

1. McDonald J, Bayrak-Toydemir P, Pyeritz RE. Hereditary hemorrhagic telangiectasia: an overview of diagnosis, management, and pathogenesis. Genet Med. 2011;13(7):607616.

2. Fuchizaki U, Miyamori H, Kitagawa S, Kaneko S, Kobayashi K. Hereditary haemorrhagic telangiectasia (Rendu-Osler-Weber disease). Lancet. 2003;362(9394):1490-1494.

3. Letarte M, McDonald ML, Li C, et al. Reduced endothelial secretion and plasma levels of transforming growth factor-beta1 in patients with hereditary hemorrhagic telangiectasia type 1. Cardiovasc Res. 2005;68(1):155-164.

4. Sadick H, Riedel F, Naim R, et al. Patients with hereditary hemorrhagic telangiectasia have increased plasma levels of vascular endothelial growth factor and transforming growth factor-beta1 as well as high ALK1 tissue expression. Haematologica. 2005;90(6):818-828.

5. Gallione CJ, Richards JA, Letteboer T, et al. SMAD4 mutations found in unselected HHT patients. J Med Genet. 2006;43(10):793-797.

6. Karnezis TT, Davidson TM. Efficacy of intranasal bevacizumab (Avastin) treatment in patients with hereditary hemorrhagic telangiectasia associated epistaxis. Laryngoscope. 2011;121(3):636-638.
7. Riss D, Burian M, Wolf A, Kranebitter V, Kaider A, Arnoldner C. Intranasal submucosal bevacizumab for epistaxis in hereditary hemorrhagic telangiectasia: A double blind, randomized, placebo controlled trial. Head Neck. 2015;37(6):783-787.

8. Iyer VN, Apala DR, Pannu BS, et al. Intravenous Bevacizumab for Refractory Hereditary Hemorrhagic TelangiectasiaRelated Epistaxis and Gastrointestinal Bleeding. Mayo Clin Proc. 2018;93(2):155166.

9. Olitsky SE. Hereditary hemorrhagic telangiectasia: diagnosis and management. Am Fam Physician. 2010;82(7):785-790.

10. Duncan BW, Kneebone JM, Chi EY, et al. A detailed histologic analysis of pulmonary arteriovenous malformations in children with cyanotic congenital heart disease. J Thorac Cardiovasc. 1999;117(5):931-938.

11. Prigoda NL, Savas S, Abdalla SA, et al. Hereditary haemorrhagic telangiectasia: mutation detection, test sensitivity and novel mutations. I Med Genet. 2006;43(9):722-728.

12. Bossler AD, Richards J, George C, Godmilow L, Ganguly A. Novel mutations in ENG and ACVRL1 identified in a series of 200 individuals undergoing clinical genetic testing for hereditary hemorrhagic telangiectasia (HHT): correlation of genotype with phenotype. Hum Mutat. 2006;27(7):667675.
13. Klaus DJ, Gallione CJ, Kara A, et al. Nove missense and frameshift mutations in the activin receptor-like kinase-1 gene in hereditary hemorrhagic telangiectasia. Hum Mutat. 1998;12(2):137.

14. Guerrero-Esteo M, Sanchez-Elsner $T$, Letamendia A, Bernabeu C. Extracellular and cytoplasmic domains of endoglin interact with the transforming growth factorbeta receptors I and II. J Biol Chem. 2002;277(32):29197-29209.

15. Li DY, Sorensen LK, Brooke BS, et al Defective angiogenesis in mice lacking endoglin. Science. 1999;284(5419):15341537

16. Oh SP, Seki T, Goss KA, et al. Activin receptor-like kinase 1 modulates transforming growth factor-beta 1 signaling in the regulation of angiogenesis. Proc Natl Acad Sci USA. 2000;97(6):2626-2631.

17. Massague J. TGF-beta signal transduction. Annu Rev Biochem. 1998;67:753-791.

18. Abdalla SA, Letarte M. Hereditary haemorrhagic telangiectasia: current views on genetics and mechanisms of disease. J Med Genet. 2006;43(2):97-110.

19. Richards-Yutz J, Grant K, Chao EC, Walther SE, Ganguly A. Update on molecular diagnosis of hereditary hemorrhagic telangiectasia. Hum Genet. 2010;128(1):61-77.

20. Kuhnel T, Wirsching K, Wohlgemuth W, Chavan A, Evert K, Vielsmeier V. Hereditary Hemorrhagic Telangiectasia. Otolaryngol 
Clin North Am. 2018;51(1):237-254

21. Albiñana V, Zafra MP, Colau J, et al. Mutation affecting the proximal promoter of Endoglin as the origin of hereditary hemorrhagic telangiectasia type 1. BMC Med Genet. 2017;18(1):20

22. Cole SG, Begbie ME, Wallace GM, Shovlin CL. A new locus for hereditary haemorrhagic telangiectasia (HHT3) maps to chromosome 5. J Med Genet. 2005:42(7):577-582.

23. Bayrak-Toydemir P, McDonald J, Akarsu N, et al. A fourth locus for hereditary hemorrhagic telangiectasia maps to chromosome 7. Am J Med Genet A. 2006;140(20):21552162.

24. Hernandez F, Huether R, Carter L, et al. Mutations in RASA1 and GDF2 identified in patients with clinical features of hereditary hemorrhagic telangiectasia. Hum Genome Var. 2015;2:15040.

25. Shovlin CL. Hereditary haemorrhagic telangiectasia: pathophysiology, diagnosis and treatment. Blood Rev. 2010;24(6):203219.

26. Goumans M-J, Liu Z, Ten Dijke P. TGF- $\beta$ signaling in vascular biology and dysfunction. Cell Res. 2009;19(1):116-127.

27. Fernández-L A, Sanz-Rodriguez F, Blanco FJ, Bernabéu C, Botella LM. Hereditary hemorrhagic telangiectasia, a vascular dysplasia affecting the TGF- signaling pathway. Clin Med Res. 2006;4(1):66-78.

28. Pomeraniec L, Hector-Greene M, Ehrlich M, Blobe GC, Henis YI. Regulation of TGFreceptor hetero-oligomerization and signaling by endoglin. Mol Biol Cell. 2015:26(17):3117-3127

29. Scharpfenecker M, van Dinther M, Liu Z, et al. BMP-9 signals via ALK1 and inhibits bFGF-induced endothelial cell proliferation and VEGF-stimulated angiogenesis. J Cell Sci. 2007;120(6):964-972.

30. Cunha SI, Magnusson PU, Dejana E, Lampugnani MG. Deregulated TGFbeta/BMP Signaling in Vascular Malformations. Circ Res. 2017;121(8):981999.

31. Tual-Chalot S, Oh P, Arthur HM. Mouse Models of Hereditary Haemorrhagic Telangiectasia: Recent Advances and Future Challenges. Front Genet. 2015;6:25

32. Garrido-Martín EM, Blanco FJ, Roquè M, et al. Vascular Injury Triggers Krüppel-Like Factor 6 (KLF6) Mobilization and Cooperation with Sp1 to Promote Endothelial Activation through Upregulation of the Activin Receptor-Like Kinase 1 (ALK1) Gene. Circ Res. 2012;112(1):113-127.

33. Cirulli A, Liso A, D'Ovidio F, et al. Vascular endothelial growth factor serum levels are elevated in patients with hereditary hemorrhagic telangiectasia. Acta Haematol. 2003;110(1):29-32.

34. Shao ES, Lin L, Yao Y, Bostrom KI. Expression of vascular endothelial growth factor is coordinately regulated by the activin-like kinase receptors 1 and 5 in endothelial cells. Blood. 2009;114(10):21972206.

35. Han C, Choe S-w, Kim YH, et al. VEGF neutralization can prevent and normalize arteriovenous malformations in an animal model for hereditary hemorrhagic telangiectasia 2 . Angiogenesis. 2014;17(4):823-830.

36. Iannuzzi MC, Hidaka $N$, Boehnke $M$, et al. Analysis of the relationship of von Willebrand disease (vWD) and hereditary hemorrhagic telangiectasia and identification of a potential type IIA vWD mutation (IIe865 to Thr). Am J Hum Genet.
1991:48(4):757-763

37. Marchuk DA. Genetic abnormalities in hereditary hemorrhagic telangiectasia. Curr Opin Hematol. 1998;5(5):332-338.

38. Westermann CJ, Rosina AF, de Vries V, Coteau PAd. The prevalence and manifestations of hereditary hemorrhagic telangiectasia in the Afro Caribbean population of the Netherlands Antilles: A family screening. Am J of Med Genet. 2003;116(4):324-328.

39. Williams J-CB, Hamilton JK, Shiller M, Fischer L, Deprisco G, Boland CR. Combined juvenile polyposis and hereditary hemorrhagic telangiectasia. Proc (Bayl Univ Med Cent). 2012;25(4):360-364

40. Baert A. Vascular Embolotherapy: A Comprehensive Approach, Volume 1: General Principles, Chest, Abdomen, and Great Vessels: Springer Science \& Business Media, 2006

41. Donaldson JW, McKeever TM, Hall IP, Hubbard RB, Fogarty AW. Complications and mortality in hereditary hemorrhagic telangiectasia: A population-based study. Neurology. 2015;84(18):1886-1893.

42. Sabba C, Pasculli G, Suppressa P, et al. Life expectancy in patients with hereditary haemorrhagic telangiectasia. OJM. 2006;99(5):327-334.

43. Kjeldsen AD, Vase P, Green A. [Hereditary hemorrhagic telangiectasia. A populationbased study on prevalence and mortality among Danish HHT patients]. Ugeskr Laeger. 2000;162(25):3597-3601.

44. Shovlin CL, Guttmacher AE, Buscarini E, et al. Diagnostic criteria for hereditary hemorrhagic telangiectasia (Rendu Osler Weber syndrome). Am J Med Genet. 2000;91(1):6667

45. Garg N, Khunger M, Gupta A, Kumar N Optimal management of hereditary hemorrhagic telangiectasia. J Blood Med. 2014;5:191-206.

46. Brydon HL, Akinwunmi J, Selway R, UlHaq I. Brain abscesses associated with pulmonary arteriovenous malformations. Br Neurosurg. 1999;13(3):265-269.

47. Cho D, Kim S, Kim M, et al. Two cases of high output heart failure caused by hereditary hemorrhagic telangiectasia. Korean Circ J. 2012;42(12):861-865.

48. Dupuis-Girod S, Ginon I, Saurin I-C, et al Bevacizumab in patients with hereditary hemorrhagic telangiectasia and severe hepatic vascular malformations and high cardiac output. JAMA. 2012;307(9):948-955.

49. OS AA, Friedman CM, White RI Jr. The natural history of epistaxis in hereditary hemorrhagic telangiectasia. Laryngoscope. 1991;101(9):977-980.

50. Jessurun $G$, Kamphuis D, Van der Zande F Nossent J. Cerebral arteriovenous malformations in the Netherlands Antilles: high prevalence of hereditary hemorrhagic telangiectasia-related single and multiple cerebral arteriovenous malformations. Clin Neurol Neurosurg. 1993:95(3):193-198.

51. Morgan T, McDonald J, Anderson C, et al. Intracranial hemorrhage in infants and children with hereditary hemorrhagic telangiectasia (Osler-Weber-Rendu syndrome). Pediatrics. 2002;109(1):E12.

52. Press OW, Ramsey PG. Central nervous system infections associated with hereditary hemorrhagic telangiectasia. Am J Med. 1984;77(1):86-92.

53. Dong SL, Reynolds SF, Steiner IP. Brain abscess in patients with hereditary hemorrhagic telangiectasia: case report and literature review. J Emerg Med. 2001;20(3):247251.
54. Gallione CJ, Repetto GM, Legius E, et al. A combined syndrome of juvenile polyposis and hereditary haemorrhagic telangiectasia associated with mutations in $\mathrm{MADH} 4$ (SMAD4). Lancet. 2004;363(9412):852-859.

55. Jelsig AM, Torring PM, Kjeldsen AD, et al. JP-HHT phenotype in Danish patients with SMAD4 mutations. Clin Genet. 2016;90 (1):55-62.

56. Pierucci P, Lenato GM, Suppressa P, et al. A long diagnostic delay in patients with hereditary haemorrhagic telangiectasia: a questionnaire-based retrospective study. Orphanet J Rare Dis. 2012;7(1):33.

57. Harvey RJ, Kanagalingam J, Lund VJ. The impact of septodermoplasty and potassiumtitanyl-phosphate (KTP) laser therapy in the treatment of hereditary hemorrhagic telangiectasia-related epistaxis. Am I Rhinol. 2008;22(2):182-187

58. Reh DD, Yin LX, Laaeq K, Merlo CA. A new endoscopic staging system for hereditary hemorrhagic telangiectasia. Int Forum Allergy Rhinol; 2014: Wiley Online Library; 2014. p. 635-639.

59. Kwaan HC, Silverman S. Fibrinolytic activity in lesions of hereditary hemorrhagic telangiectasia. Arch Dermatol. 1973;107(4): 571-573.

60. Watanabe M, Hanawa S, Morishima T. Fibrinolytic activity in cutaneous lesions of hereditary hemorrhagic telangiectasia. Jpn J Dermatol B. 1985;95(1):11.

61. Zaffar N, Ravichakaravarthy T, Faughnan ME, Shehata N. The use of anti-fibrinolytic agents in patients with HHT: a retrospective survey. Ann Hematol. 2015;94(1):145152.

62. Geisthoff UW, Seyfert UT, Kubler M, Bieg B, Plinkert PK, Konig J. Treatment of epistaxis in hereditary hemorrhagic telangiectasia with tranexamic acid - a double-blind placebo-controlled cross-over phase IIIB study. Thromb Res. 2014;134(3):565-571

63. Fernandez-L A, Garrido-Martin EM, SanzRodriguez F, et al. Therapeutic action of tranexamic acid in hereditary haemorrhagic telangiectasia (HHT): Regulation ofALK1/endoglin pathway in endothelial cells. Thromb Haemost. 2007;97(2):254-262.

64. de Gussem EM, Snijder RJ, Disch FJ, Zanen $\mathrm{P}$, Westermann CJ, Mager JJ. The effect of Nacetylcysteine on epistaxis and quality of life in patients with HHT: a pilot study. Rhinology. 2009;47(1):85-88.

65. Longacre $\mathrm{AV}$, Gross CP, Gallitelli $M$ Henderson KJ, White Jr RI, Proctor DD Diagnosis and management of gastrointestinal bleeding in patients with hereditary hemorrhagic telangiectasia. Am J Gastroenterol. 2003:98(1):59-65.

66. Nardone G, Rocco A, Balzano T, Budillon G The efficacy of octreotide therapy in chronic bleeding due to vascular abnormalities of the gastrointestinal tract. Aliment Pharmacol Ther. 1999;13(11):1429-1436.

67. Livesey JA, Manning RA, Meek JH, et al. Low serum iron levels are associated with elevated plasma levels of coagulation factor VIII and pulmonary emboli/deep venous thromboses in replicate cohorts of patients with hereditary haemorrhagic telangiectasia. Thorax. 2012;67(4):328-333

68. Peng HL, Yi YF, Zhou SK, Xie SS, Zhang GS Thalidomide Effects in Patients with Hereditary Hemorrhagic Telangiectasia During Therapeutic Treatment and in FliEGFP Transgenic Zebrafish Model. Chin Med J (Engl). 2015;128(22):3050-3054.

69. Bauditz J, Schachschal G, Wedel S, Lochs $\mathrm{H}$. Thalidomide for treatment of severe 
intestinal bleeding. Gut. 2004;53(4):609612.

70. Lebrin F, Srun S, Raymond K, et al. Thalidomide stimulates vessel maturation and reduces epistaxis in individuals with hereditary hemorrhagic telangiectasia. Nat Med. 2010;16(4):420-428.

71. Gordon M, Margolin K, Talpaz M, et al. Phase I safety and pharmacokinetic study of recombinant human anti-vascular endothelial growth factor in patients with advanced cancer. J Clin Oncol. 2001;19(3):843-850.

72. Dupuis-Girod S, Ambrun A, Decullier E, et al. ELLIPSE Study: a Phase 1 study evaluating the tolerance of bevacizumab nasal spray in the treatment of epistaxis in hereditary hemorrhagic telangiectasia. Mabs. 2014:6(3):794-799.

73. Kim YH, Kim MJ, Choe SW, Sprecher D, Lee Y, P Oh S. Selective effects of oral antiangiogenic tyrosine kinase inhibitors on an animal model of hereditary hemorrhagic telangiec- tasia. J Thromb Haemost. 2017;15(6):1095 1102.

74. Ruiz S, Chandakkar P, Zhao $\mathrm{H}$, et al. Tacrolimus rescues the signaling and gene expression signature of endothelial ALK1 loss-of-function and improves HHT vascular pathology. Hum Mol Genet. 2017;26(24): 4786-4798.

75. Samour M, Saygin, C., Abdallah, R., Kundu, S., McCrae, K.R. Pomalidomide in Hereditary Hemorrhagic Telangiectasia: Interim Results of a Phase I Study. Blood. 2016;128(22):210

76. Warkentin TE, Moore JC, Morgan DG. Gastrointestinal angiodysplasia and aortic stenosis. N Engl J Med. 2002;347(11):858859.

77. Bose P, Holter JL, Selby GB. Bevacizumab in hereditary hemorrhagic telangiectasia. N Engl J Med. 2009;360(20):2143-2144.

78. Oosting S, Nagengast W, de Vries E. More on bevacizumab in hereditary hemorrhagic telangiectasia. N Engl J Med. 2009;361(9): 931; author reply 931-932.

79. Brinkerhoff BT, Poetker DM, Choong NW. Long-term therapy with bevacizumab in hereditary hemorrhagic telangiectasia. N Engl J Med. 2011;364(7):688-689.

80. Thompson AB, Ross DA, Berard P, FigueroaBodine J, Livada N, Richer SL. Very low dose bevacizumab for the treatment of epistaxis in patients with hereditary hemorrhagic telangiectasia. Allergy Rhinol (Providence) 2014;5(2):91-95.

81. Epperla N, Kapke JT, Karafin M, Friedman $\mathrm{KD}$, Foy P. Effect of systemic bevacizumab in severe hereditary hemorrhagic telangiectasia associated with bleeding. Am J Hematol. 2016;91(6):E313-314.

82. Guilhem A, Fargeton AE, Simon AC, et al Intra-venous bevacizumab in hereditary hemorrhagic telangiectasia (HHT): A retrospective study of 46 patients. PLoS One 2017;12(11):e0188943. 